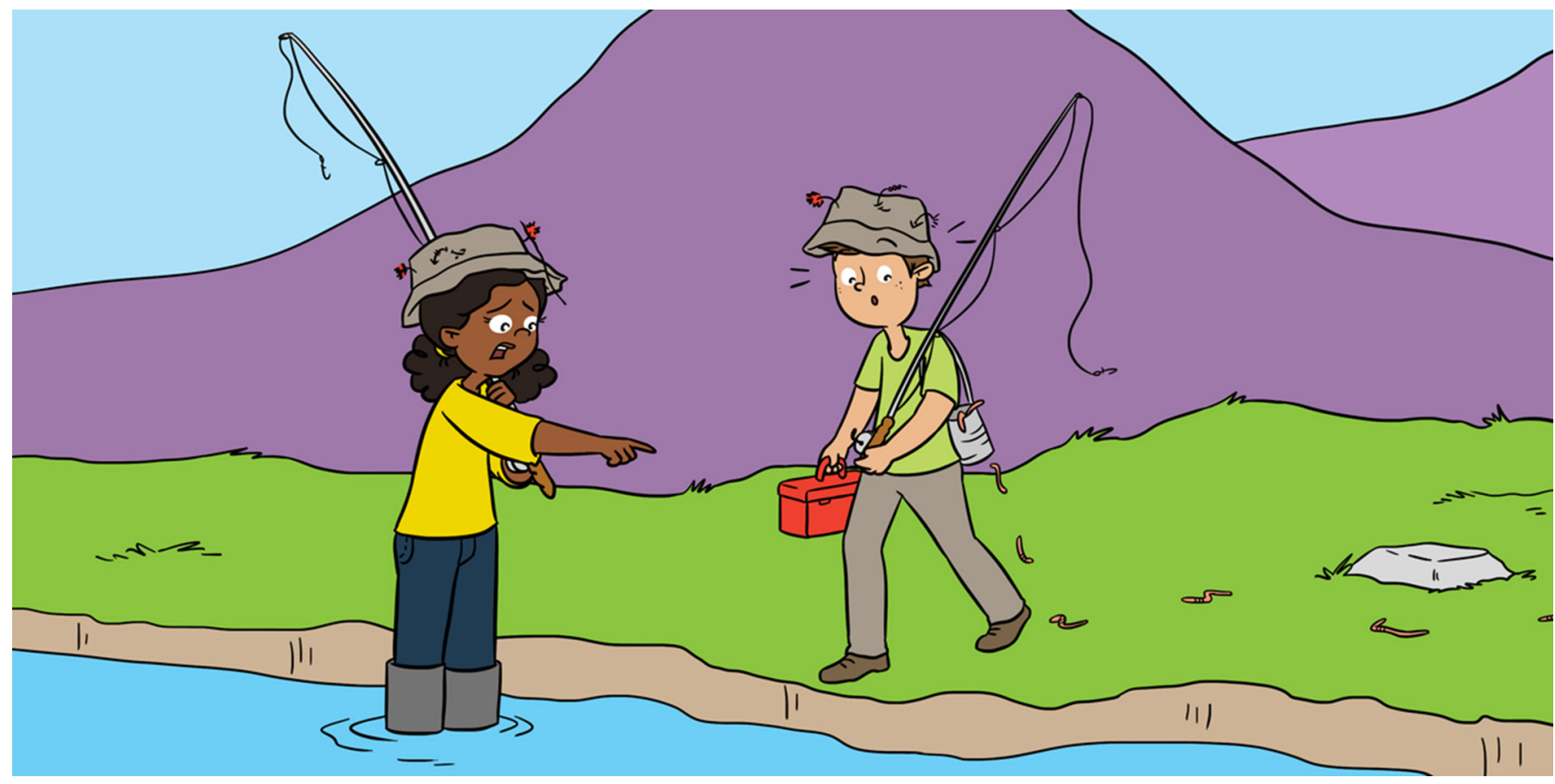

\title{
HOW INTRODUCED EARTHWORMS ALTER ECOSYSTEMS
}

\author{
Malte Jochum ${ }^{1,2^{*}}$ and Nico Eisenhauer ${ }^{1,2}$ \\ ${ }^{1}$ German Centre for Integrative Biodiversity Research (iDiv) Halle-Jena-Leipzig, Leipzig, Germany \\ ${ }^{2}$ Institute of Biology, Leipzig University, Leipzig, Germany
}

YOUNG REVIEWERS:

LILU

AGE: 10

MICHELLE

AGE: 16
We all know earthworms as important friends in our garden: they help plants to grow better by providing nutrients, water, and air in the soil. However, in some cases, earthworms have more negative effects. This is because other organisms need to be used to the activities of earthworms to benefit from their presence. Some regions of the world have developed without earthworms for over thousands of years. For example, in northern North America, earthworms have been absent for more than 10,000 years and have only been re-introduced over the past $\sim 400$ years. In many cases, introduced earthworms find a perfect environment, because no other organisms have been able to use the resources that these earthworms now consume. As so-called ecosystem engineers, earthworms dramatically alter many ecosystem characteristics. In this article, we summarize the known consequences of earthworm invasion, report on how scientists study these, and highlight remaining knowledge gaps that you might help solving should you decide to become an ecologist. 
ECOSYSTEM

\section{FUNCTION}

A process that takes place in an ecosystem and either represents, or is driven by, the activity of organisms. Examples include the decomposition of organic material, nutrient cycling, or water retention.

\section{PERTURBATION}

A disturbance, in ecology usually a disturbance to an equilibrium state, or any level of biological organization (individual, population, community, ecosystem).

\section{BIODIVERSITY}

The variety of life on earth, usually measured as variability at the genetic, species, or ecosystem level.

\section{ECOSYSTEM}

\section{ENGINEER}

An organism that modifies its environment by redistributing material and energy via non-feeding interactions with living and dead components of its ecosystem.

\section{BURROWING}

Tunnel-building activity of earthworms.

\section{CASTING}

The activity of building small piles of earthworm droppings on the soil surface and in the soil.

\section{MIXING}

The activity of redistributing different parts of the soil with each other and organic material from the soil surface.

\section{INTERACTING ORGANISMS HELP ECOSYSTEMS PROVIDE SERVICES TO HUMANS}

Within an ecosystem, different species interact, for example by eating, helping, or providing habitat for each other. Every species consumes its resources and is eaten by other species. They all have their unique roles in nature. Some species have particularly important roles in ecosystems because they eat dead leaves or animals. These species recycle materials and provide them back to the ecosystem. Other organisms help plants to produce flowers and seeds. All organisms carry out ecosystem functions, such as decomposition, pollination, and many others. We humans rely on the functions and services that intact ecosystems provide to us. However, these services depend on the diversity and interactions of the species present. Perturbations to an ecosystem can alter its biodiversity and the interactions of species within it. Changing climate (e.g., higher temperature), altered land use (e.g., transforming forests into agricultural fields), or species invasions (the introduction of new species to an ecosystem) all have the potential to disrupt ecosystems in ways that can alter their functions and the services they provide.

\section{INVASIVE SPECIES CHANGE ECOSYSTEMS}

An invasive species is a species that arrives in a new environment, establishes itself, substantially increases in abundance, and forms novel interactions there, significantly altering the invaded ecosystem. Species invasions are one of the most important causes of global biodiversity change. Invaded ecosystems are changed by things like the establishment of new feeding relationships, the replacement of natural plants by dominating invasive plants, the disappearance of previously-established species, or the facilitation of further invasions. The effects of species invasions are strongest if the invasive species differs a lot from the species already living in the ecosystem [1]. Differences could include resource use, robustness to stressors, growth speed, or the ability to eat food that the other species cannot digest. Some invasive species have particularly strong effects because they actively alter their environment by creating or modifying habitats. Such species are called ecosystem engineers. Examples are beavers, which build dams and temporarily turn terrestrial habitats into freshwater ones, and earthworms, which alter soils by burrowing (building tunnels), casting (building small piles of their droppings on and in the soil), and mixing dead plant material on the ground with the soil below [2]. 
1 Clay video by Maxwell Helmberger: https://www. youtube.com/watch? $\mathrm{v}=3 \mathrm{a}$ 7IFGOYL7s 8 list=PLB9tSz89_6 -qBS8RRFOh5Yzhy C31KJHOC\& index $=5$

\section{EARTHWORMS ARE VERY IMPORTANT FOR SOIL ECOSYSTEMS-IN A GOOD OR BAD WAY}

Earthworms naturally occur in most terrestrial ecosystems around the globe. They constantly structure the soils that they live in. Their burrowing activities mix the soil and improve the flow of air and water through the underground world. By eating dead organic material from the soil surface, dragging it down into the soil, digesting it, and then leaving their droppings, they redistribute nutrients throughout the soil. These activities affect other life below and above the ground. The altered air, water, and nutrient availability changes how other organisms can use their resources, where they can live, and how well they can grow and reproduce. Through these activities, earthworms influence bacteria, fungi, springtails, mites, beetles, plants, and even animals that live above the soil surface, such as aphids. Consequently, earthworms are very important soil organisms ${ }^{1}$ with impacts beyond the belowground world. This is fine in areas where the other organisms are used to having earthworms around, but it can become problematic where they are not used to these squishy neighbors.

\section{INVASIVE EARTHWORMS ARE A GLOBAL ISSUE}

In many places, earthworms are considered "the gardener's best friend." They commonly improve soil quality in gardens, fields, meadows, and forests. Other organisms have shared these ecosystems with the earthworms for a very long time, and are used to their presence and activity. Hundreds of earthworms and up to a dozen earthworm species per square meter can be found in these ecosystems, but this is not the case everywhere in the world. Some places have a low number of earthworms, and in other areas earthworms are completely absent [3]. In areas where earthworms are naturally rare or absent, introduced earthworm species can become a big problem [4]. This is because, in these places, microbial, plant, and animal species are not used to having earthworms around. The native species may not be able to deal with the changes the earthworms make to the soil's water, air, and nutrient availability. It is important to study the effects of earthworm invasion on ecosystems and predict their future impact because it is impossible to remove earthworms from areas where they have established without killing other animals and plants.

\section{NORTHERN NORTH AMERICA IS BEING INVADED BY EARTHWORMS}

Huge parts of the northern USA and Canada were covered by vast ice sheets during the last glaciation period (Figure 1). Under these ice sheets, earthworms could not survive. Thus, at least since the ice disappeared about 12,000 years ago, most of North America has been 


\section{Figure 1}

Approximate extent of the northern North American ice shield during the last glacier period. The graph at the lower left shows the approximate maximum thickness of the ice sheet in comparison to the highest building in North America 546 m, One World Trade Center, New York City, USA). The thickness of the ice sheet varied across time and space during the glaciation. Original satellite image by NASA, from wikipedia.org.
2 MinuteEarth video: https://www. youtube.com/ watch?v= icGV8bJRkkg

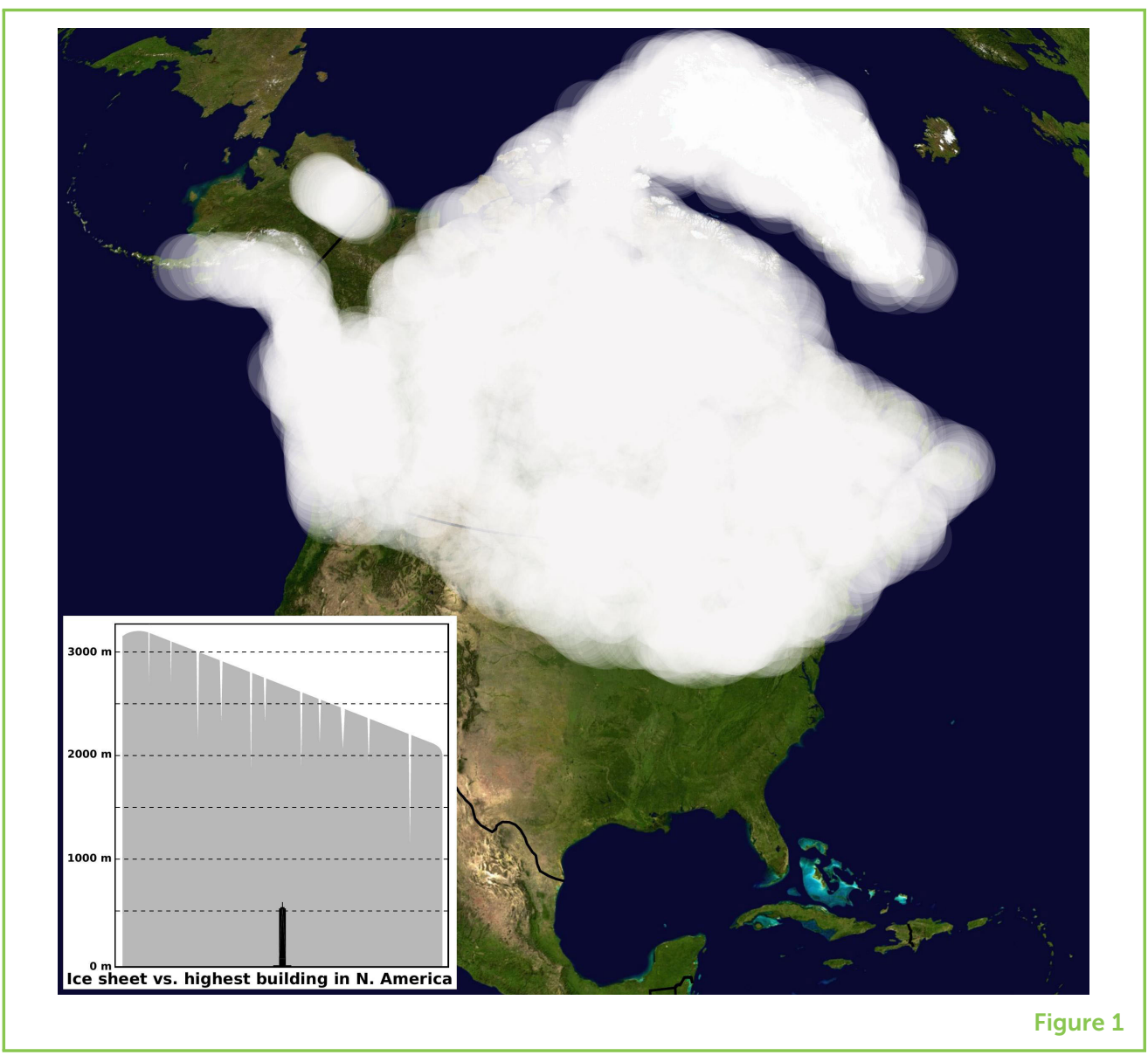

naturally earthworm-free. Natural reintroduction of earthworms takes a long time, because they spread slowly into new habitats $(<10 \mathrm{~m}$ per year). However, when the European settlers arrived in North America, they accidentally and/or intentionally brought earthworms with them ${ }^{2}$. Once introduced, the earthworms liked many of these areas a lot. The forests had thick layers of not-yet-decomposed organic matter (dead remains of formerly living stuff), which was a great feast for the earthworms (Figure 2). They made themselves at home and their numbers grew rapidly. By building roads, moving soil, moving plants, and similar activities, the settlers actively distributed earthworms throughout the northern part of the continent much faster than the earthworms could have traveled on their own. In some areas, earthworms were likely introduced by fishermen, who may have dropped their unused bait close to lakes, streams, or fishing cabins. As a result, the spread of earthworms was helped by humans who did not know or did not care what ecosystem-scale effects these newcomers would have. 
Figure 2

Illustration of how invasive earthworms alter previously earthworm-free ecosystems. By burrowing, feeding on leaf litter, and mixing soil, earthworms affect the soil properties causing changes in soil layers, vegetation, and soil organisms. These changes affect ecosystem processes, such as

greenhouse-gas emissions and loss of nitrogen ( $\mathrm{N}$ leaching) from the soil.

Increasing atmospheric levels of

greenhouse-gases, e.g., carbon dioxide or nitrous oxide, are an environmental issue. Different functional groups of soil animals, shown in the black center box (size groups from large to small: macrofauna-e.g., spiders and woodlice; mesofauna-e.g., springtails and mites; microfauna-e.g., nematodes, and microorganisms-e.g., bacteria and some fungi), are affected by the three ecological groups of earthworms (epigeic-live in leaf litter and on the soil surface,

endogeic-build mostly horizontal burrows in upper soil layers, and anecic-build deep, vertical burrows; see right panel). What changes can you spot? Originally published in Ferlian et al. [5], reproduced with the permission of the original publisher.

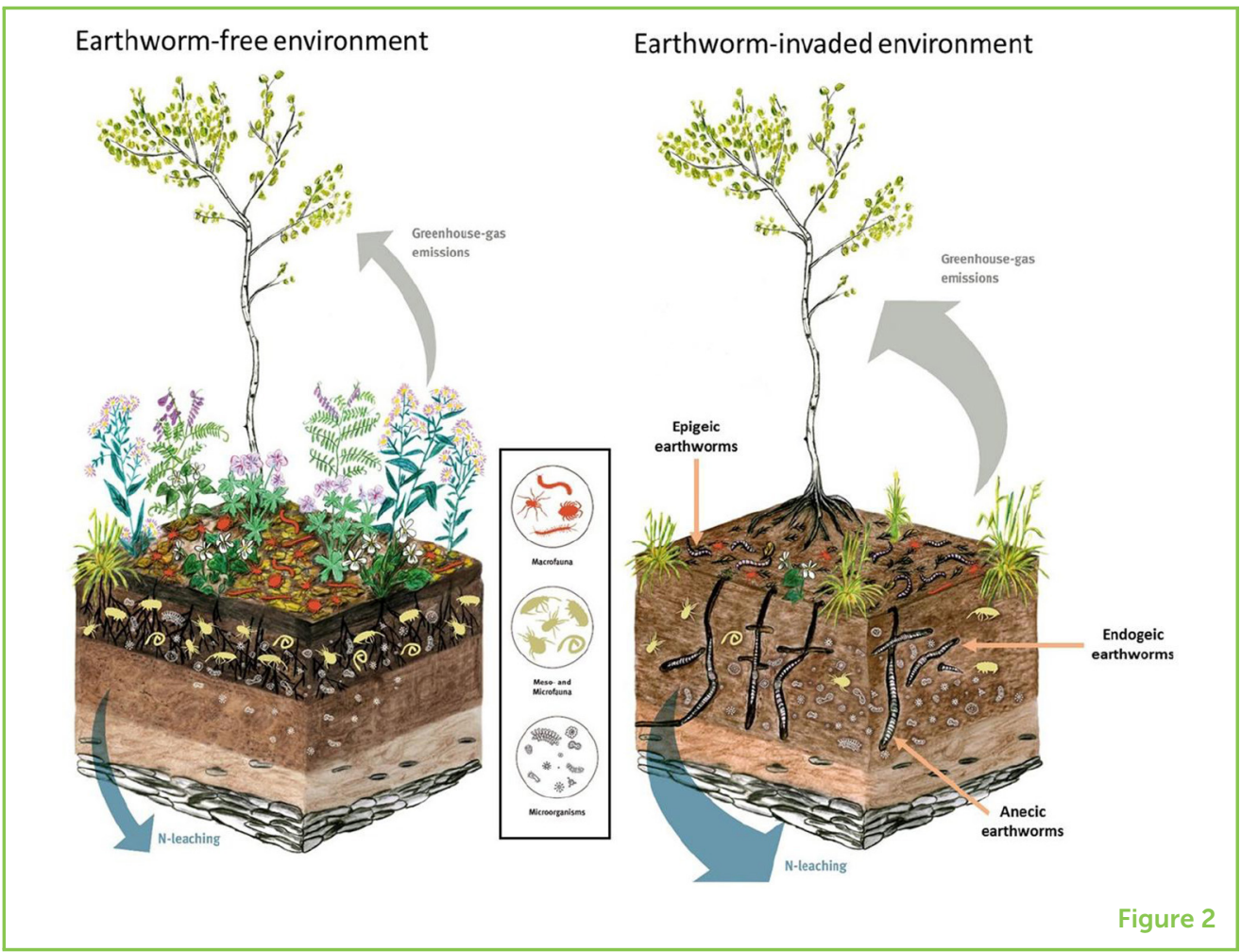

\section{RESEARCHERS STUDY HOW EARTHWORMS CHANGE ECOSYSTEMS}

Scientists have been studying earthworm invasions for many decades, using three different approaches: First, in field observation studies, researchers compare uninvaded to similar, already invaded ecosystems. Second, in field experiments, researchers compare small areas without earthworms to areas nearby where they experimentally release earthworms. Alternatively, they first measure ecosystem properties, then release earthworms there and then measure the same properties again. Another approach is to keep small patches of soil and plants in laboratories under controlled conditions, with light, water, and temperature controlled by researchers. Some patches then receive earthworms and others do not so that they can be directly compared. In all these approaches, researchers can assess the ways that earthworms change ecosystems, such as how earthworms alter the physical, chemical, and biological properties of soils, and various ecosystem functions. All these different approaches and measurements help us to better understand how invasive earthworms change their new homes.

\section{WHAT DO WE ALREADY KNOW?}

We already know quite a lot about how earthworms change the chemical and physical properties of the soil. Earthworms create soils that are warmer, drier, and less acidic, and they alter the availability 
Figure 3

Extreme example of the potential

consequences of earthworm invasion in a maple forest in Minnesota, USA. The upper panel shows an uninvaded forest area, the lower panel shows a forest area invaded by European earthworms. Photo credit: Ulrich Pruschitzki (top) and Olga Ferlian (bottom), altered after [6].

\section{PHYSICAL SOIL PROPERTY}

Soil properties related to matter, energy, or force. For example, the water or air content.

\section{CHEMICAL SOIL PROPERTY}

Soil properties related to elements and compounds of atoms, molecules, and ions.

For example, the availability of different nutrients and elements, or acidity.

\section{BIOLOGICAL SOIL PROPERTY}

Soil properties related to living things. For example, the number of species present, their biomasses,

or interactions

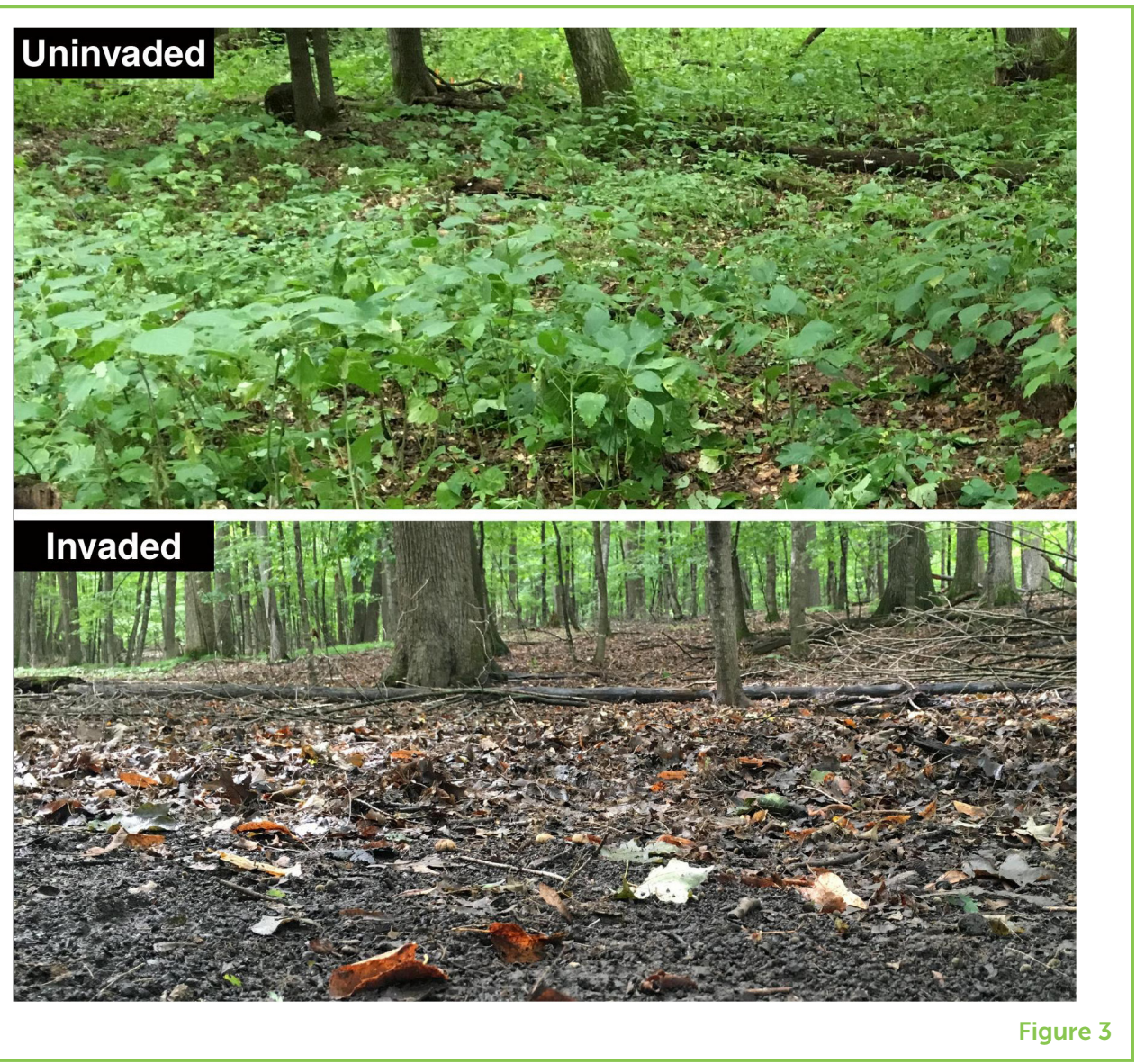

of soil nitrogen and carbon, two very important chemical elements. In addition, earthworm invasion often reduces the number of other soil organisms and the number of different animal and plant species (Figures 2, 3). Not all organisms are negatively affected though. For example, oribatid mites and springtails are often reduced, but prostigmatid mites are increased where earthworms have invaded. Also, some species locally disappear, but other species, particularly those that are used to the presence of earthworms, might follow the earthworms' example and become invasive. Earthworm invasion can cause a cascade of ecosystem consequences that are also relevant to humans, such as altered water quality and the likelihood of forest fires [6]. We know that invasive earthworms reduce the number of plant species, but they increase the importance of grass-like plants and the number of non-native plants. Earthworms also influence large animals, such as salamanders and birds that nest on the soil surface. While some salamanders can use earthworm burrows to hide and feed on earthworms, the nests of ground-nesting birds can be destroyed by earthworms burying leaf litter, which is the primary nest-building material. 
3 EcoWorm project introduction video: https://www. youtube.com/ watch? $v=\mathrm{Au}_{-}$ VYDUhAw\&list= PLJFvA_Py3UkyUbNO4 8 W7bY2KoVuSYIlec finde $=10 \& t=0 s$

\section{EARTHWORM INVASION RESEARCH CONTINUES ...}

It takes time to study ecosystem responses to perturbations-studies often need to run for many years. This is why, despite decades of research on the effects of invasive earthworms on their new homes, there is still a lot that we do not know $[7]^{3}$. We know more about how earthworm invasion affects the physical structure, other organisms, and ecosystem functions below the ground than above. We also do not know a lot about how earthworm invasion changes the way above- and below-ground systems interact, or how energy flows through the networks of organisms eating each other. While we know how earthworm invasion alters the plant community as a whole, we do not know much about how it influences the characteristics of individual plants, such as the size of their leaves, which is very important for plant life and function (e.g., photosynthesis). Most of our knowledge is based on observational studies and laboratory experiments because field experiments are often difficult to run and require special care to make sure the worms cannot escape and invade previously uninvaded areas. Finally, you probably know that our planet's climate is rapidly changing. Higher temperatures and changing intensity of rain can interact with earthworm invasions. It is therefore important to study what happens when organisms in an ecosystem must simultaneously cope with a combination of higher temperature, changing precipitation patterns, and their new squishy neighbors. Curious young minds like you can help answering these questions and further unravel the secret details of life below the ground, especially in response to species invasions and their impacts on the ecosystems of our ever-changing planet.

\section{AUTHOR CONTRIBUTIONS}

MJ drafted the text and figures and NE contributed to the writing and discussion of the content.

\section{ACKNOWLEDGMENTS}

We were very grateful for the constructive comments of two Science Mentor-Young Reviewer pairs and Associate Editor Nathan M. Good which have substantially improved our manuscript. We acknowledge funding by the European Research Council under the European Union's Horizon 2020 research and innovation program (grant no 677232 to Nico Eisenhauer) and the German Centre for Integrative Biodiversity Research Halle-Jena-Leipzig, funded by the German Research Foundation (FZT 118). 


\section{REFERENCES}

1. Wardle, D. A., Bardgett, R. D., Callaway, R. M., and Van der Putten, W. H. 2011. Terrestrial ecosystem responses to species gains and losses. Science 332:1273-7. doi: 10.1126/science.1197479

2. Eisenhauer, N., and Eisenhauer, E. 2020. The "intestines of the soil": the taxonomic and functional diversity of earthworms-a review for young ecologists. EcoEvoRxiv. doi: 10.32942/osf.io/tfm5y

3. Phillips, H. R. P., Guerra, C. A., Bartz, M. L. C., Briones, M. J. I., Brown, G., Crowther, T. W., et al. 2019. Global distribution of earthworm diversity. Science 366:480-5. doi: 10.1101/587394

4. Hendrix, P. F., Callaham, M. A. Jr., Drake, J. M., Huang, C. Y., James, S. W., Snyder, B. A., et al. 2008. Pandora's box contained bait: the global problem of introduced earthworms. Annu. Rev. Ecol. Evol. Syst. 39:593-613. doi: 10.1146/annurev.ecolsys.39.110707.173426

5. Ferlian, O., Eisenhauer, N., Aguirrebengoa, M., Camara, M., Ramirez-Rojas, I., Santos, F., et al. 2018. Invasive earthworms erode soil biodiversity: a meta-analysis. J. Anim. Ecol. 87:162-72. doi: 10.1111/1365-2656.12746

6. Frelich, L. E., Blossey, B., Cameron, E. K., Dávalos, A., Eisenhauer, N., Fahey, T., et al. 2019. Side-swiped: ecological cascades emanating from earthworm invasions. Front. Ecol. Environ. 17:502-10. doi: 10.1002/fee.2099

7. Eisenhauer, N., Ferlian, O., Craven, D., Hines, J., and Jochum, M. 2019. Ecosystem responses to exotic earthworm invasion in northern North American forests. Res. Ideas Outcomes 5:e34564. doi: 10.3897/rio.5.e34564

SUBMITTED: 12 February 2020; ACCEPTED: 13 October 2020; PUBLISHED ONLINE: 09 December 2020.

EDITED BY: Nathan M. Good, University of California, Berkeley, United States

CITATION: Jochum M and Eisenhauer N (2020) How Introduced Earthworms Alter Ecosystems. Front. Young Minds 8:534345. doi: 10.3389/frym.2020.534345

CONFLICT OF INTEREST: The authors declare that the research was conducted in the absence of any commercial or financial relationships that could be construed as a potential conflict of interest.

COPYRIGHT () 2020 Jochum and Eisenhauer. This is an open-access article distributed under the terms of the Creative Commons Attribution License (CC BY). The use, distribution or reproduction in other forums is permitted, provided the original author(s) and the copyright owner(s) are credited and that the original publication in this journal is cited, in accordance with accepted academic practice. No use, distribution or reproduction is permitted which does not comply with these terms. 

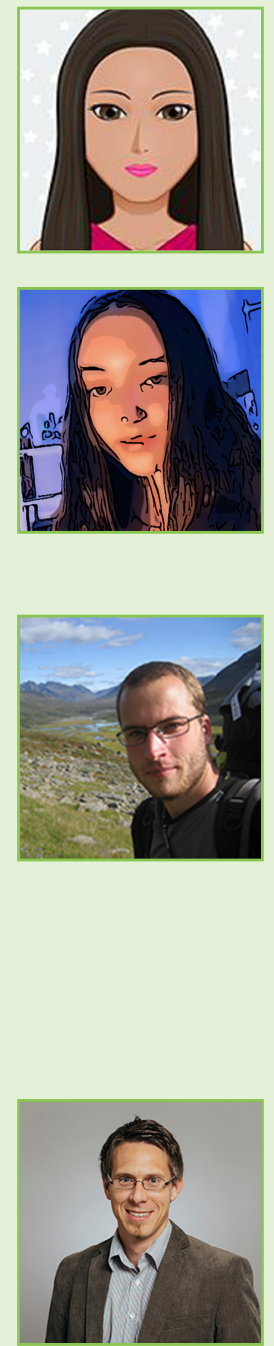

\section{YOUNG REVIEWERS}

\section{LILU, AGE: 10}

I love polar bears and I am fighting against Climate Change to save them! I love guinea pigs too.

\section{MICHELLE, AGE: 16}

I am a Spanish girl who wants to be a pilot. At school, my favorite subjects are Biology and Maths. My hobbies are aviation and playing tennis.

\section{AUTHORS}

\section{MALTE JOCHUM}

Malte studied biology because, as a teenager, he built a small pond in his parents' garden and realized that this subject would never cease to amaze him. As a community ecologist, he is very interested in how human activities affect plant and animal communities and their functioning. His work has focused on aquatic and terrestrial ecosystems across temperate and tropical areas and mainly involves macroinvertebrates. When not at work, he likes to explore nature with his two daughters, do rock climbing, cycling, or canoeing, and more recently, has discovered an interest in beginner-level triathlon. *malte.jochum@idiv.de

\section{NICO EISENHAUER}

Nico has been interested in nature since early childhood. He dug for earthworms, caught frogs and fish, and helped lizards survive the winter months. He has always been fascinated by the beauty of nature and driven by the question of why a specific plant or animal species occurs at one place, but not at another place. During his study of biology, he discovered his interest in the distribution of biological diversity, particularly in the soil, and how it affects the functioning of ecosystems. When not at work, Nico likes soccer, badminton, running, and spending time with his family and friends. 